\title{
DISPERSAL OF THE PEARLY EYE BUTTERFLY AT THE PAS, MANITOBA
}

WALTER KRIVDA, Box 864, The Pas, Manitoba. R9A $1 \mathrm{~K} 8$

I have known of the presence of the Pearly Eye (Enodia portlandia borealis (Clark) ) in The Pas area for almost 30 years now. It is a shy species of shaded woods, taken now and then along Grace Lake, east of town.

It was something of a surprise to Paul and Franklin Chermock in 1962 when they visited here to find it this far north in Canada. It was therefore, a greater surprise this summer to find for the first time the Pearly Eye ranging widely, and out of its woodland habitat. The cool, overcast summer may have encouraged this wider local dispersal. A specimen was taken in the author's backyard in mid July fully three miles away from its native woodland habitat where even in an average year, a good deal of hunting is needed even to see an individual.

The Pearly Eye was also seen in Preachard's woods across from the Scott Bateman Collegiate in town. This also is three miles away from its usual area of occurrence.

Mr. Phil Reader took a specimen of the Pearly Eye at Reader Lake in July. This is an area from which it has never been seen before. It is also an unlikely habitat. The area is underlain by sands grown over with Jack Pine and White Spruce. The specimens may have originated from the sedge meadow bordering Reader Lake at this point.

Only in 1962 was the Pearly Eye abundant in this area, that being an acre or so of ground at Big Eddy on the bottom slopes of the hill going down to Pike Lake, an area that has a sunny exposure but is well timbered. Generally speaking with the above exception it is a scarce butterfly in The Pas area.
The summer was so cool in The Pas area that for the first time in a quarter of a century, tomatoes failed in gardens in town. This is a fairly sensitive and observable signal of weather change. The previous year was also below normal in summer heat. Cool overcast summers may well affect the dispersal of shade loving species of butterflies.

To reverse the thinking, the sudden dispersal and establishment of shade loving butterfly species could be used as corroborative information of a drop in normal summer heat and normal sun light intensity. This may well be worth looking into, in some detail. The volcanic dust in the upper atmosphere and local forest fires last year may have blocked sufficient heat energy from reaching the ground to have produced this local response in the Pearly Eye.

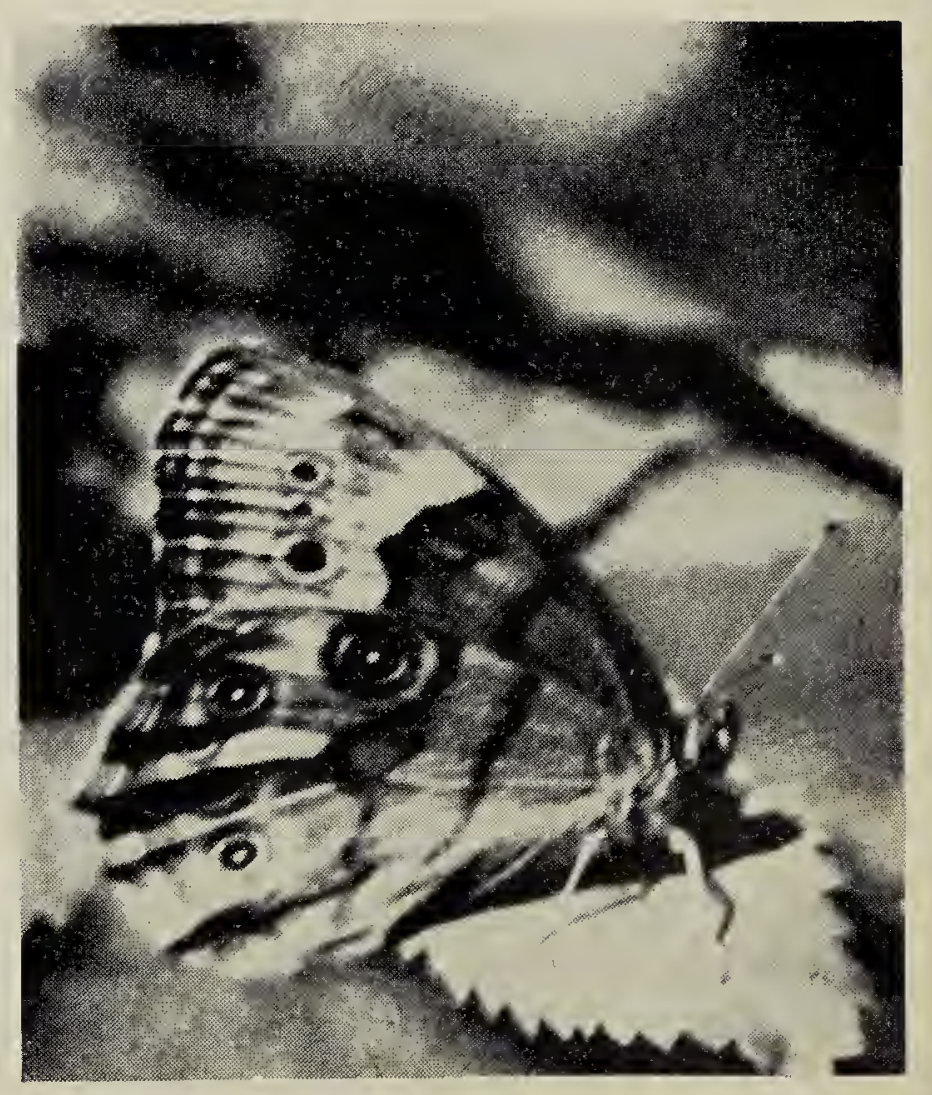

Pearly Eye

D. Hooper 